\title{
La economía política del déficit fiscal en el Chile del siglo XIX
}

\author{
Roberto Pastén
}

\section{Resumen}

A mediados de la década de 1860, se observó en Chile un cambio estructural en la tendencia, que muestra déficits fiscales más elevados. Para algunos autores esto obedeció al aumento del gasto derivado del rápido crecimiento de la economía. Otra explicación común es que fue necesario aumentar el gasto para financiar la guerra contra España. En este artículo se plantea, como explicación alternativa, que se debió principalmente a una creciente agitación política a comienzos de la segunda mitad del siglo XIX, que terminó con la destitución del Presidente Balmaceda en 1891. Esta hipótesis es congruente con la idea de que la inestabilidad política tiende a llevar a un desacoplamiento entre los ingresos tributarios y los gastos, dos elementos que, de otra manera, se mantendrían alineados, tal como predice la teoría del suavizamiento de impuestos (tax smoothing). En este ensayo se presenta una descripción fáctica que apoya dicha hipótesis.

\section{Palabras clave}

Política fiscal, déficit presupuestario, presupuestos nacionales, historia económica, Chile Clasificación JEL

$\mathrm{H} 21, \mathrm{H} 62$

Autor

Roberto Pastén es Ministro Titular del Tercer Tribunal Ambiental y Profesor Adjunto del Instituto de Economía de la Universidad Austral de Chile, Valdivia, Chile. roberto.pasten@uach.cl 


\section{Introducción}

Los patrones que siguieron los gastos y los ingresos fiscales de Chile entre 1833 y 1891 a todas luces ponen de relieve un cambio de tendencia hacia mediados de la década de 1860 (véase el gráfico 1). Aunque dicho cambio haya sido documentado en escasas ocasiones, algunos investigadores igualmente han tomado nota de él (Collier y Sater, 2004; Cortés, Butelmann y Videla, 1981; Humud, 1969). Por ejemplo, en A History of Chile, 1808-2002, Collier y Sater (2004) plantean que antes de finalizada la década de 1850, los ministros de hacienda no tenían dificultades para equilibrar el presupuesto. Sin embargo, a partir de 1860 el gasto comenzó a superar el ritmo de crecimiento del comercio y se tornó más difícil cubrir los gastos recurriendo a las fuentes "ordinarias" (es decir, las que contaban con aprobación legislativa). La recaudación de tributos internos sufrió una merma como proporción de los ingresos del Estado. Hubo una fuerte renuencia a imponer gravámenes sobre los bienes o las rentas (de hecho, las tasas de los impuestos internos bajaron durante este período), y, aunque el Estado ahora recaudaba fondos por la prestación de algunos servicios propios, como los ferrocarriles, ya no podía llegarse a un equilibrio de las cuentas sin recurrir al préstamo (Collier y Sater, 2004, pág. 76).

\section{Gráfico 1}

Chile: ingresos y gastos fiscales, 1833-1891

(En porcentajes del producto interno bruto)

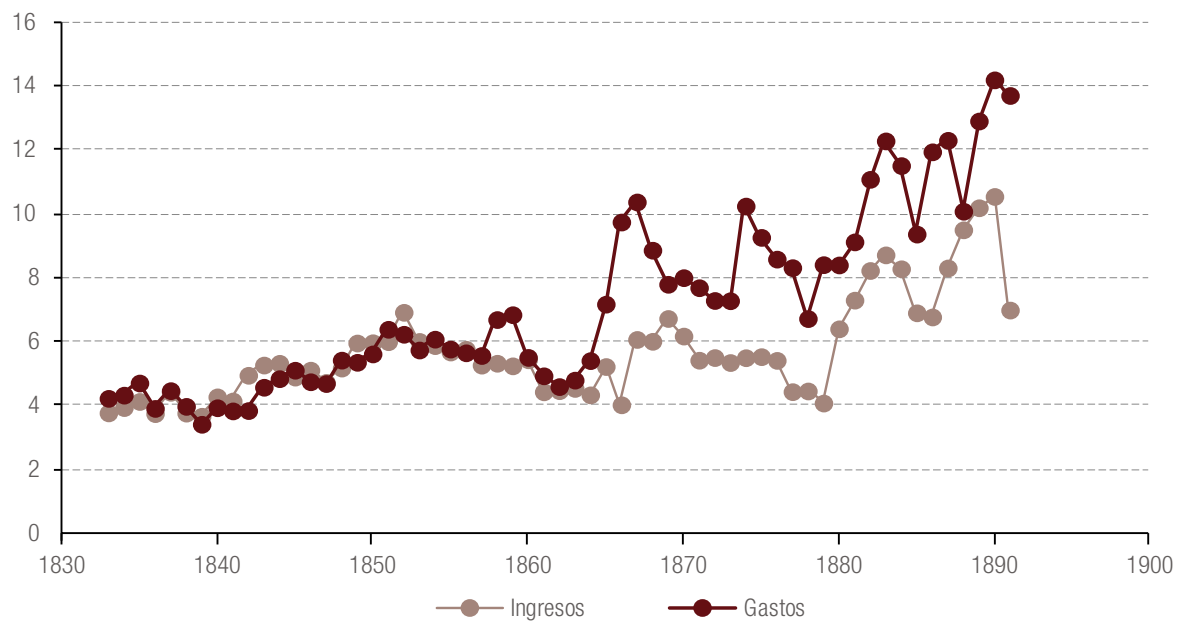

Fuente: G. Wagner, J. Jofré y R. Lüders, “Economía chilena 1810-1995. Cuentas fiscales”, Documento de Trabajo, № 188, Santiago, Pontificia Universidad Católica de Chile, 2000.

Humud (1969) también presenta evidencia de un cambio estructural en las cuentas fiscales chilenas a comienzos de la segunda mitad del siglo XIX. Plantea que en los primeros años de vida de la República, la actividad del sector público se vio limitada en función del crecimiento de los ingresos fiscales. No obstante, hacia la segunda mitad del siglo XIX, el incremento de las actividades del sector público y la participación en nuevos ámbitos, como la construcción de caminos y el tendido de vías ferroviarias, llevó a aumentar el gasto público con independencia de los ingresos.

A fin de evaluar la significancia estadística de este cambio en el déficit fiscal y evitar cualquier sesgo asociado con un cambio estructural predeterminado, se utiliza la prueba de Bai y Perron (Bai, 1997; Bai y Perron, 1998 y 2003) para determinar en forma endógena en qué momento se produjo un cambio estructural en las series de déficit fiscal chileno que van de 1833 a 1891. Los resultados muestran que a mediados de la década de 1860 se llega al punto más alto del test, lo que revela que en ese momento hubo un cambio en la serie (véase el gráfico 2). 


\section{Gráfico 2}

Chile: déficit fiscal (prueba de Bai y Perron del cambio estructural endógeno), 1833-1891

(En porcentajes del producto interno bruto)

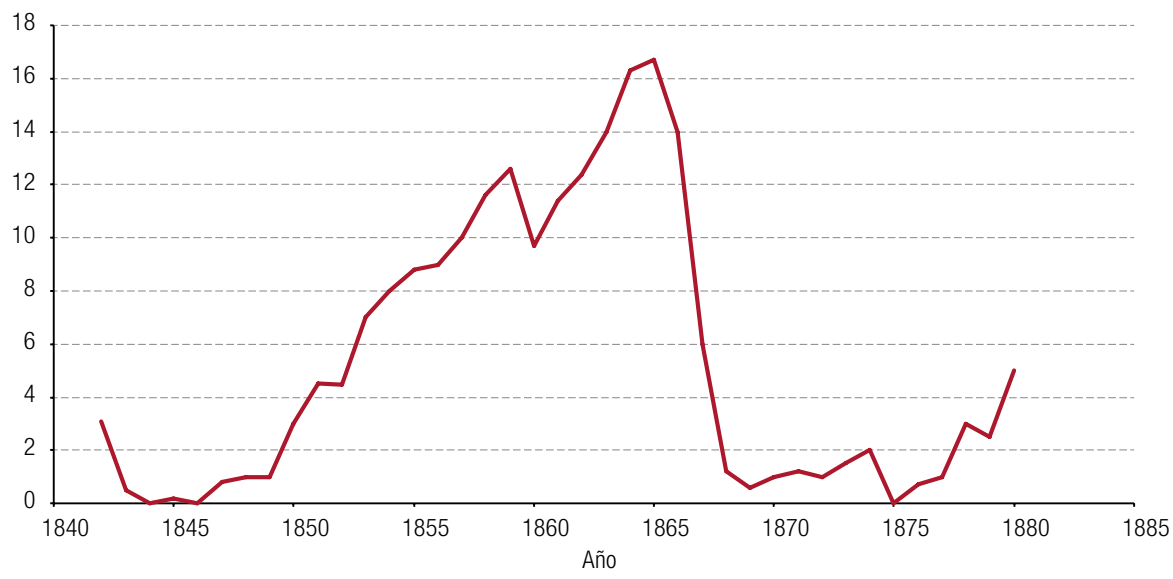

Fuente: Elaboración propia, sobre la base de G. Wagner, J. Jofré y R. Lüders, "Economía chilena 1810-1995. Cuentas fiscales", Documento de Trabajo, № 188, Santiago, Pontificia Universidad Católica de Chile, 2000.

Dada la sólida evidencia de que el déficit fiscal chileno sufrió un cambio estructural durante el siglo XIX, de inmediato surge la pregunta: ¿qué factores trajeron aparejado este cambio repentino en el proceso fiscal a inicios de la década de $1860^{1}$ ?

Se han postulado diversos argumentos para dar cuenta de este cambio. Según algunos autores, este déficit más profundo tuvo origen en el mayor gasto público necesario para seguir el ritmo de crecimiento del comercio (Cáceres, 2000; Robles-Ortiz, 2010; Cortés, Butelmann y Videla, 1981). Sin embargo, en este sentido se plantea que la evidencia solo brinda un fundamento parcial a este punto de vista, pues, como se muestra en las próximas secciones, el comercio había estado creciendo desde mucho antes de 1861, al menos desde que las fuerzas chilenas derrotaron a la Confederación Peruano-Boliviana en 1839. Además, si la turbulencia de la política fiscal se debió solo al crecimiento económico, ¿por qué el gasto militar - la segunda mayor partida presupuestaria - no creció al mismo ritmo que el resto de la economía? Este es un hecho de la historia chilena profusamente documentado, que tuvo repercusiones graves al inicio de las hostilidades con los países vecinos en 1879 (Collier y Sater, 2004).

Otra explicación habitual de la profundización del déficit es el mayor gasto requerido para financiar la guerra contra España, que comenzó en 1864, y recuperarse después de sus consecuencias (Corbo y Hernández, 2005). Esta teoría también carece de fundamentos sólidos, dado que, en todo sentido, esa guerra fue limitada y no convencional. No hubo combates en territorio chileno y los países beligerantes se enfrentaron en tan solo dos batallas navales. El conflicto terminó al cabo de dos años con el bombardeo de la ciudad portuaria de Valparaíso, un acontecimiento que indiscutiblemente afectó durante un tiempo la producción nacional y el gasto público; sin embargo, resulta difícil justificar en estos hechos los 25 años de desarreglo fiscal que siguieron a la finalización de la guerra.

En este artículo se presenta una interpretación diferente de los problemas fiscales: en gran medida tuvieron origen en la mayor agitación política ocurrida durante la segunda mitad del siglo XIX, que representó un alejamiento radical de los primeros años de vida de la República más calmos y prósperos. Varios autores, como Collier (2003), Collier y Sater (2004), Stuven (1997), Cavieres (2001), Castedo (2001) y Galdames (1964), han señalado que los inicios de la década de 1860 fueron un período de profundo realineamiento político.

1 Véase un análisis general de la economía chilena del siglo XIX en Díaz, Lüders y Wagner (2007). 
La hipótesis de que la inestabilidad política constituye una de las posibles causas del desarreglo fiscal es congruente con el marco conceptual elaborado por Pastén y Cover (2010, 2011 y 2015) sobre la base de los determinantes políticos de suavizamiento de impuestos e inclinación impositiva (tax tilting), que, en su opinión, explican los déficits en los presupuestos gubernamentales. En un contexto de suavizamiento de impuestos - equivalente a un déficit fiscal sostenible y eficiente-, para minimizar el costo social distorsionador de los impuestos, un déficit resulta eficiente si es el resultado de una decisión de política de no modificar la tasa impositiva en respuesta a las fluctuaciones transitorias del gasto gubernamental. Por el contrario, la inclinación impositiva tiene lugar cuando el gobierno tiene el incentivo de descontar el costo social de los impuestos a una tasa superior a la que los descuenta la sociedad, por lo que pospone impuestos o adelanta gastos, desencadenando así una tendencia ascendente en los déficits fiscales. El argumento principal de Pastén y Cover es que la inclinación impositiva es una función positiva de la inestabilidad política. El mecanismo de transmisión funciona de la siguiente manera: un incremento de la inestabilidad política, medido por la probabilidad de perder el poder, aumenta la tasa a la que el gobierno descuenta costos sociales futuros; es decir, en el caso de la inclinación impositiva, una política fiscal gubernamental relativamente más miope produce una tendencia hacia mayores déficits fiscales. Asimismo, los autores muestran que la relación causal va de la política (inestabilidad política) a los déficits, más que en el sentido inverso (Pastén y Cover, 2010 y 2015).

Otros autores también han postulado la existencia de un vínculo entre la inclinación impositiva y la inestabilidad política. Cashin, Haque y Olekalns (1999, pág. 14) plantean que la inclinación impositiva podría ocurrir, por ejemplo, si el gobierno que exista en ese momento no está seguro de sus posibilidades de ser reelecto, por lo que favorece niveles de deuda corriente más elevados de los que entraña el suavizamiento de impuestos².

Un análisis más minucioso del gráfico 1 también parece brindar cierto sustento a la hipótesis de que la inestabilidad política constituye un determinante de la inclinación impositiva: en primer lugar, al menos a partir de 1851, los ingresos tributarios (como porcentaje del producto interno bruto (PIB)) comenzaron a descender antes del punto de inflexión mencionado en este articulo y antes de la crisis de 1873, lo que, a simple vista, parece incongruente con la hipótesis de que los desarreglos fiscales comenzaron a mediados de la década de 1860. No obstante, en el gráfico 1 también se observa con claridad que a inicios de la década de 1850 no solo cayeron los impuestos, sino también el gasto total, y que ambas variables continuaron un curso común descendente hasta mediados de la década de 1860. Esto se condice con la hipótesis planteada en este artículo de que en condiciones de estabilidad política, no se observan efectos de inclinación impositiva, y que en el largo plazo las variaciones en los impuestos y el gasto se dan en forma conjunta. Además, según se observa en el gráfico 1, el gasto sobrepasa el ritmo de los impuestos solo en forma transitoria en 1859, muy probablemente a causa de una breve guerra civil desatada ese año al finalizar la presidencia de Manuel Montt. Ese efecto fue transitorio, porque, si bien la tributación se mantuvo relativamente constante, el gasto aumentó durante un lapso corto con el propósito de financiar la guerra civil de 1859, lo que es típico del suavizamiento de impuestos, pero no de la inclinación impositiva. Asimismo, en el gráfico 1 se observa que en la segunda mitad de la década de 1860 el gasto supera en forma radical a los impuestos, lo que sí caracteriza a la inclinación impositiva.

En segundo lugar, si bien tras la guerra del Pacífico (1879-1883) Chile logró obtener el control de zonas ricas en nitratos que tenían el Perú y Bolivia, lo que incrementó los ingresos recaudados, el problema del déficit fiscal persistió al menos hasta 1891 (véase el gráfico 1). Este hecho brinda un sustento sólido a la hipótesis presentada en este artículo, porque ni siquiera la mayor recaudación obtenida tras la guerra del Pacífico bastó para compensar el aumento del gasto fiscal que, según

\footnotetext{
2 Véase un punto de vista similar en Cerda y Vergara (2008). Si se desea consultar evidencia empírica relativa a América Latina, véase Pastén y Cover (2015), y evidencia acerca del caso de Chile, Pastén y Cover (2010).
} 
esta hipótesis, podría explicarse por la fragilidad política de un gobierno desesperado por lograr más apoyo político de cara a la guerra civil de 1891.

Por último, a partir de mediados de la década de 1860, los mayores déficits derivaron principalmente del incremento del gasto; sin embargo, no queda claro qué componente del gasto propició dicho incremento. Aunque la explicación trasciende el propósito de este análisis, los trabajos de Humud (1969) pueden arrojar algo de luz sobre este cambio en la composición, que guarda congruencia con la hipótesis planteada en este artículo. Humud halló que antes de 1860, el gasto fiscal crecía a una tasa del 5,5\% (en comparación con la tasa del 6,2\% de los ingresos tributarios), sobre todo para financiar el gasto administrativo y convencional. No obstante, el gasto luego creció a un ritmo del 5,7\% entre 1860 y 1879, y del 3,4\% de 1880 a 1900 (en comparación, los ingresos aumentaron un $4,8 \%$ y un $2,8 \%$, respectivamente). Este aumento se originó, sobre todo, en un grupo de nuevos componentes del gasto fiscal, el principal de ellos las obras públicas -en particular el tendido de líneas ferroviarias -, así como la justicia, la educación y los gastos bélicos. El gasto en obras públicas es un signo de clientelismo, según plantea Rogoff (1990) en sus modelos de ciclos políticos presupuestarios, donde describe la preferencia de los gobiernos por los proyectos de gran visibilidad inmediata. González (2002) observó un sesgo político similar en México y mostró que el Gobierno manipuló la política fiscal con fines políticos antes de todas las elecciones federales. La variable de política utilizada fue el gasto en infraestructura.

En la sección II se mostrará que, en la historia de la política y las finanzas públicas chilenas del siglo XIX, la hipótesis de que la tendencia de los déficits fiscales se vio influenciada por el contexto político resulta razonable. Se presenta una descripción breve y muy estilizada de los acontecimientos políticos y económicos que dan forma al período que va de 1833 a 1860, con el objeto de mostrar que fue una época de políticas fiscales sólidas y de estabilidad política. En la sección III se describen los acontecimientos políticos y económicos ocurridos entre 1861 y 1891, un período caracterizado por crisis fiscales y una incertidumbre política intensa y creciente que llegó a su punto máximo con la guerra civil, que finalizó con el suicidio del Presidente José Manuel Balmaceda en 1891. Por último, en la sección IV se exponen las conclusiones.

\section{1833-1860: una época de orden y progreso}

Ya en 1818, cuando Chile declaró su independencia de España, surgieron dos movimientos políticos que propugnaban puntos de vista opuestos sobre la sociedad: por un lado, los liberales ("pipiolos"), que representaban fielmente las doctrinas liberales europeas, y, por el otro, los conservadores ("pelucones"), que eran principalmente terratenientes y representaban el legado español en el país.

Sus ideas antagónicas respecto de cómo debía organizarse la nueva República llevaron a constantes enfrentamientos en el período inmediatamente posterior a la independencia de España. Tras la batalla de Lircay (1830), los conservadores prevalecieron por sobre los liberales, y se adoptó una Constitución que favoreció un Poder Ejecutivo fuerte, en sintonía con las ideas del Ministro Diego Portales.

Después de la batalla de Lircay, Diego Portales surgió como una suerte de Alexander Hamilton chileno ${ }^{3}$. Al ocupar en forma conjunta los cargos de Ministro del Interior, Relaciones Exteriores y Guerra, diseñó y apoyó una Constitución que preconizaba un sistema presidencialista y centralizado. La Constitución de 1833, si bien fue objeto de algunas reformas, estuvo vigente durante casi 100 años

\footnotetext{
3 Las similitudes entre estos dos hombres llaman la atención: fácilmente podrían haber llegado a la presidencia, pero ninguno se postuló para ocupar el cargo, abogaron por un gobierno fuerte y centralizado y murieron de manera trágica entre los 40 y los 50 años de edad.
} 
(hasta 1925). Establecía que el presidente podía ocupar el cargo durante dos mandatos quinquenales consecutivos, motivo por el cual, por ejemplo, durante 40 años solo se eligieron cuatro presidentes. El presidente controlaba el gabinete, el Poder Judicial, la administración pública y las fuerzas armadas, y también gozaba de poderes de emergencia, como la facultad de declarar, cuando el Congreso nacional estaba en receso, el estado de sitio en cualquier parte del territorio. En virtud de dichos poderes de emergencia, el presidente podía suspender las garantías constitucionales en el territorio afectado. Además, como la Constitución de 1833 era sumamente centralista, no se permitía ninguna asamblea federalista y los jefes provinciales eran nombrados por el presidente, que también tenía derecho a vetar las decisiones de los concejos municipales elegidos.

Este período (1833-1860) se caracterizó, en particular, por la organización de un Estado con extraordinaria estabilidad, eficacia y resistencia. Además, fue una época de progreso económico sostenido. Otro rasgo fue el intervencionismo electoral, que en la práctica permitía a cualquier gobierno elegir a los miembros del Congreso y al sucesor presidencial. El electorado era pequeño - solo tenían derecho a elegir representantes los propietarios de cierto número de bienes - y los oficiales militares podían influenciar el voto de sus soldados reteniéndoles el certificado de registro electoral hasta el día de las elecciones (Collier y Sater, 2004). No obstante, hubo cierta oposición, sobre todo de parte de los diputados que nunca tuvieron una mayoría en el Congreso. El régimen conservador fue más religioso que secular y durante la primera mitad del siglo XIX no tuvo que hacer frente a ninguna oposición. Al menos hasta la década de 1850, no existió ninguna resistencia política significativa ${ }^{4}$.

El punto de consenso entre liberales y conservadores era la gran importancia que otorgaban al orden social, algo que el Ministro Portales describió con elocuencia: "La República debía ser un gobierno fuerte, centralizador, cuyos hombres sean modelos de virtud y patriotismo, y así enderezar a los ciudadanos por el camino del orden y de las virtudes"5. Aquí radica la justificación del riguroso control de la prensa, los cambios en la organización del Ejército y las severas políticas públicas. Según Portales, el orden representaba, ante todo, el orden público y su meta final era mantener el orden social. También creía que la unión entre el Estado y la Iglesia (católica) constituía otra precondición del orden social.

Para los liberales - que eran más seglares que confesionales -, las condiciones impuestas por el régimen conservador resultaban aceptables si la alternativa era la anarquía que había caracterizado los primeros años de la República. Andrés Bello y otros liberales destacados dieron su apoyo al régimen autoritario de los gobiernos conservadores. La clase política suprimía de inmediato todo atisbo de oposición. Por ejemplo, El Progreso (el primer periódico de Santiago) publicó: "En Chile [...] no hay voluntad nacional que expresar, porque no hay partidos en pugna, ni cuestiones vitales que dividan a la sociedad"6.

Respecto del consenso predominante y la autoimposición de límites al disenso, Collier y Sater (2004, pág. 104) señalaron que el liberalismo, en tanto que fuerza política coherente, en esos años (1833-1850) estuvo cerca de perecer como consecuencia de su propia complacencia.

\section{Una época de progreso económico}

Cuando Chile se independizó de España en 1818, el monopolio español llegó a su fin y el flujo comercial viró sobre todo hacia el Reino Unido y, en menor medida, hacia Francia y Alemania. Las nuevas corrientes comerciales trajeron aparejada la apertura de sucursales de compañías británicas

4 En 7 de las 11 elecciones legislativas celebradas entre 1833 y 1864, la oposición se abstuvo o casi ni se molestó en presentar candidatos. Centró sus esfuerzos en la Cámara de Diputados, pero solo logró la elección de unos pocos legisladores después de 1860 (Collier, 2003).

5 Ernesto de la Cruz (editor), Epistolario de don Diego Portales (Santiago, Ediciones de la Biblioteca Nacional, 1936), pág. 177 (citado en Stuven, 1997, págs. 269-270).

6 El Progreso, 10 de junio de 1844 (citado en Stuven, 1997, pág. 280). 
en los principales puertos y ciudades de Chile. Sin embargo, fue el programa de reformas económicas llevado adelante por el Ministro de Hacienda de Portales, Manuel Rengifo, el instrumento que hacia 1830 afianzó un camino de desarrollo basado en la apertura al comercio mundial.

Rengifo (que se desempeñó como Ministro de Hacienda de 1830 a 1835 y de 1841 a 1844) tuvo como meta equilibrar las cuentas fiscales, objetivo que se alcanzó en 1839 gracias a los crecientes ingresos aduaneros.

Desde un punto de vista económico, las políticas de Rengifo resultaron más neoclásicas que neomercantilistas, pues propiciaron el crecimiento del comercio. En 1834, la legislación comercial reforzó la tendencia descendente de los aranceles que se venían aplicando a las importaciones desde la independencia. El arancel medio era del 25\% (Sutter y Sunkel, 1982) ${ }^{7}$.

Las reformas puestas en marcha por el Ministro Rengifo se condecían con una economía abierta al comercio mundial y tuvieron como resultado un extraordinario aumento de los ingresos tributarios. Eliminó la mayoría de los derechos de exportación, salvo el $4 \%$ en el caso del trigo y el $6 \%$ en el de los minerales). Sin embargo, el mayor estímulo al comercio internacional fue una medida que habían intentado adoptar todos los gobiernos desde 1813: la creación de almacenes públicos o fiscales. Gracias a esta iniciativa, se autorizó a las empresas mercantiles a almacenar mercancías en el puerto de Valparaíso a un costo reducido, para que luego las comercializaran cuando las condiciones del mercado fueran favorables. En 1833, el plazo de almacenamiento se extendió de tres a seis años. En ese momento, Valparaíso se convirtió en uno de los puertos más importantes del Pacífico meridional (solo superado por el puerto del Callao, en el Perú) y el principal puerto para los buques que cruzaban por el cabo de Hornos. La victoria de Chile sobre el Perú y Bolivia en la guerra contra la Confederación Peruano-Boliviana (1836-1839) afianzó el liderazgo de Valparaíso como el principal puerto al sur de California. Este período determina la expansión del comercio internacional chileno, que hacia 1840 había triplicado los niveles de 1810 (Sutter y Sunkel, 1982).

Chile, además de llevar a cabo una apertura económica, estaba desarrollando una economía basada en los recursos naturales. En 1832, Juan Godoy descubrió Chañarcillo, una mina de plata que constituyó el hallazgo minero más extraordinario de la primera mitad del siglo XIX. Las minas de plata -y posteriormente las de cobre - contribuyeron a incrementar la población de la zona minera del Norte Chico de Chile, al tiempo que crearon un nuevo mercado para los productos agrícolas de la región meridional del país. No obstante, los ingresos fiscales procedentes de los recursos naturales nunca sobrepasaron el 10\% de la recaudación total. Hasta la finalización de la guerra del Pacífico en 1883, fueron los gravámenes y derechos aduaneros, en lugar de los impuestos sobre los recursos naturales, los que tuvieron la mayor participación en los ingresos tributarios totales.

La espectacular expansión del comercio que comenzó en 1833 fue una oportunidad para sistematizar el régimen impositivo y simplificar las normas y reglamentaciones aduaneras, así como la organización administrativa, medidas que ejercieron un potente efecto y, a su vez, aumentaron la recaudación tributaria. Chile logró no solo pagar los préstamos tomados durante la época colonial, sino que también obtuvo grandes superávits presupuestarios. Desde la presidencia de José Joaquín Prieto a comienzos de la década de 1830 hasta la de Manuel Montt a inicios de la de 1860, todos los gobiernos conservadores siguieron rigurosamente la política que tenía como objeto pagar la deuda pública en tiempo y forma. La solvencia del Estado chileno durante los regímenes conservadores fue admirable (Edwards, 1932; Galdames, 1964; Collier y Sater, 2004).

\footnotetext{
7 No obstante, en varios estudios se muestran tratamientos muy diferentes más allá del arancel medio (Cortés, Butelmann y Videla, 1981; Díaz y Wagner, 2004).
} 


\section{Una nueva crisis}

Conforme en Chile se desvanecían los recuerdos de la anarquía y ganaban terreno entre los liberales las ideas foráneas surgidas de los acontecimientos relacionados con la Revolución Francesa de 1848, el régimen conservador comenzó a toparse con diversos escollos (Stuven, 1997). Collier y Sater (2004, pág. 104) brindan una descripción precisa de los signos incipientes de un realineamiento político hacia mediados del siglo XIX. Según estos investigadores, resultaba improbable que el sistema conservador pudiera sobrevivir indefinidamente sin cambios. Cuando mediaba el siglo, se desató una batalla feroz -y a veces sangrienta- entre los defensores del estilo autoritario inicial y quienes favorecían un enfoque más liberal y tolerante del gobierno.

Por primera vez, los liberales recurrieron en 1850 a sus facultades constitucionales para diferir la aprobación de la ley anual de presupuesto, con el objeto de ejercer presión política, práctica que se intensificó a comienzos de la década de 1860 y constituyó un factor de importancia en la caída del Presidente Balmaceda en el conflicto de 1891.

El primer alzamiento significativo de la historia republicana tuvo lugar el 20 de abril de 1851, pero las fuerzas gubernamentales sofocaron la rebelión y los miembros del ejército que encabezaron los disturbios perdieron la vida en el enfrentamiento. Meses más tarde ese mismo año, Manuel Montt asumió la presidencia (1851-1861). Un sello de su gobierno fue la importancia atribuida al logro de un progreso sustancial, mediante el tendido de ferrocarriles y caminos, la apertura de nuevos territorios, la expansión de las fronteras y otros objetivos. Según Collier y Sater (2004, pág. 110), el propio Montt tal vez haya considerado su énfasis en los "intereses sustanciales" un medio para distraer a los chilenos de las preocupaciones de índole política.

Aunque el Presidente Montt no se apartó de este camino de progreso durante casi todo su gobierno, hacia fines de su mandato se observaban señales de un cambio profundo en la política chilena. Estos acontecimientos moldearían el escenario político de los años venideros y pondrían fin al período de paz, orden y progreso impuesto por los regímenes conservadores.

Estas transformaciones políticas fueron el resultado de un acontecimiento menor originado a fines de la década de 1850 por un conflicto entre la Iglesia católica y el Poder Judicial. En ese caso, el Presidente Montt -en una decisión inusual dada su postura conservadora- optó por apoyar al Poder Judicial dado su deseo de afianzar el poder presidencial. Como consecuencia, por primera vez en la historia de Chile, surgió una grieta en el Partido Conservador.

Durante el gobierno del Presidente Montt, que duró casi un decenio, parte de la clase política absorbió lentamente ideas acerca de la modernidad ilustrada y el liberalismo europeo. Según Domingo Santa María - un futuro Presidente de postura liberal reñido con la Iglesia -, entre los conservadores existían contradicciones. Stuven (1997) planteó que el reposo político de aquel momento obedecía al autoritarismo presidencial y a una anuencia excesiva de Montt hacia la Iglesia.

No obstante, el propio concepto de un conglomerado conservador y confesional se oponía a la idea de un sistema presidencial fuerte. Toda la sociedad chilena estuvo involucrada en el enfrentamiento entre el Gobierno y la Iglesia católica. Tras originarse como una disputa menor con la Iglesia, el debate se propagó a otras áreas que el público anteriormente había pasado por alto, como la educación católica y la libertad de culto. Como resultado, el partido gobernante sufrió una dura confrontación y sus miembros se dividieron en conservadores seculares y confesionales.

Del conflicto surgió una nueva y poderosa fuerza política: una combinación de liberales y conservadores descontentos con las políticas presidenciales a favor del clero. Al concluir el mandato del Presidente Montt, se reprimió un nuevo levantamiento - y más sangriento - contra el Gobierno. Sin embargo, la etapa de supremacía conservadora que había dotado al país de progreso económico y estabilidad (en particular estabilidad fiscal), había llegado a su fin. 


\section{1861-1891: un período de agitación política}

\section{El punto de inflexión}

Varios autores describen diferentes cambios estructurales ocurridos durante el período republicano entre 1833 y 1891. Para algunos, 1876 fue un importante punto de inflexión: ese año el país sufrió una de sus depresiones económicas más profundas. Según otros, la tendencia se revirtió en 1879, cuando se desató la guerra del Pacífico, mientras que otro grupo -incluido el autor de este artículocree que el cambio más significativo ocurrido en Chile durante el siglo XIX tuvo lugar cuando daba inicio la década de 1860, con el realineamiento político del Partido Conservador. Según Collier y Sater (2004, pág. 116), los acontecimientos de 1861 marcan una importante línea divisoria en la historia política de Chile. Las generaciones posteriores tendrían una mejor opinión del Presidente Montt y Varas, su Ministro del Interior, pero la clase política en general no disimuló el alivio que le despertó su partida del poder. El nuevo Presidente tenía un estilo muy diferente. Su tolerancia quizá provenía, como se comentaba en aquel entonces, de una indiferencia suprema. José Manuel Balmaceda lo describió como alguien "ebrio de indolencia". Sin embargo, estas cualidades eran precisamente las necesarias para inducir un estado de calma tras las turbulencias de la década anterior. Si bien quienes admiran los gobiernos fuertes a menudo no tienen una opinión positiva de este anciano patricio, en realidad, merece el mismo crédito que cualquier presidente del siglo XIX por haber consolidado la "idiosincrasia nacional" de la política civilizada.

Como señalan estos autores, los defensores de los regímenes fuertes que habían caracterizado los primeros años de la República abominaban del Gobierno del Presidente José Joaquín Pérez (1861-1871). Su primer mandato marca tanto el mayor realineamiento político desde el nacimiento de la República como un cambio estructural de tendencia, que muestra déficits más profundos (véase el gráfico 1).

Durante sus años en el poder, el Presidente Pérez gobernó en general teniendo como telón de fondo la Fusión Liberal-Conservadora. El distanciamiento de los regímenes autoritarios anteriores resultó evidente en varios proyectos para reformar la Constitución de 1833 (en principio, eran enmendables alrededor de 34 artículos de la Constitución). De conformidad con la Constitución de 1833, solo la legislatura siguiente podía llevar adelante una reforma constitucional, por lo que las elecciones de 1870 fueron extremadamente reñidas. El programa de reformas incluía la libertad electoral, una ampliación de las libertades individuales y un acotamiento generalizado de las prerrogativas presidenciales. No obstante, el nuevo Congreso aprobó una única enmienda, aunque de relevancia histórica: se prohibieron los mandatos presidenciales consecutivos, lo que puso fin a los gobiernos encabezados por un mandatario que permanecía en el poder durante un decenio. Esta fue la primera vez que se reformó la Constitución en 38 años.

El siguiente titular del Ejecutivo, Federico Errázuriz - que ocupó el cargo de 1871 a 1876-, asumió en septiembre. A semejanza de su predecesor, inició su mandato con el apoyo de la Fusión Liberal-Conservadora, pero cuando dejó el poder contaba solo con el respaldo de la coalición liberal. Posteriormente, la presidencia pasó a manos del Partido Liberal, hasta que Balmaceda fue depuesto en 1891.

El mandato del Presidente Errázuriz se caracterizó por una lucha política mucho más feroz que en los gobiernos anteriores. Al comienzo de su período, los miembros conservadores de su gobierno estuvieron en desacuerdo con la tendencia prevaleciente en la enseñanza pública de otorgar gran importancia a las ciencias naturales, pues consideraban que esta decisión era contraria a la creencia religiosa y que atentaba contra la moral privada (Galdames, 1964). Esta controversia acerca de cuestiones teológicas llevó al Presidente Errázuriz a apartar a los conservadores de su gobierno. Así, 
por primera vez, los conservadores se convirtieron en parte de la oposición y empezaron a tratar de ampliar la base electoral para incorporar a ciudadanos chilenos previamente excluidos (en su mayoría, católicos), en un esfuerzo por disminuir el poder presidencial. El sistema electoral se reformó para otorgar representación a los partidos minoritarios sobre la base del número de electores registrados.

Mientras tanto, el año 1870 trajo consigo un prolongado período en el que bajó el precio de los productos básicos de exportación, lo que afectó, sobre todo, al sector triguero, porque los cultivos se tornaron más productivos y aumentaron los medios de transporte de los que disponían los competidores en los mercados extranjeros (lo que desplazó a la industria exportadora de alimentos chilenos de la posición ventajosa de que gozó durante la fiebre del oro desatada en California y Australia). Además, la producción de cobre decreció a partir de 1872, al tiempo que se redujo el precio de la plata. Estos acontecimientos causaron la más profunda crisis económica padecida por la nueva República hasta el momento, que dejó secuelas duraderas en la economía. El desarrollo del sistema bancario alrededor de 1870 permitió monetizar la economía, al reemplazar el sistema obligatorio de convertibilidad del peso en oro por el uso del papel moneda. Sin embargo, la imposibilidad de convertir el papel moneda en oro condujo a la devaluación del peso chileno y agudizó su volatilidad, lo que también tuvo repercusiones políticas ${ }^{8}$. Asimismo, hay cierta evidencia de que la inconvertibilidad se puso en marcha para socorrer a algunos bancos y apoyar al Gobierno (Millar, 1994).

Hacia 1876, el precio mundial del cobre había sufrido una merma del 20\%, las exportaciones cupríferas de Chile habían menguado un 16\% y las exportaciones de plata eran un tercio de las efectuadas en 1874. En 1877, condiciones meteorológicas adversas destrozaron caminos y vías férreas, y devastaron los cultivos y el ganado, por lo que se contrajeron las exportaciones de trigo y harina. Unos 300.000 trabajadores perdieron su empleo; muchas empresas quebraron, y el precio de los alimentos sufrió un alza (Collier y Sater, 2004).

Esta contracción económica trajo aparejada una merma drástica de la recaudación tributaria. Para subsanar esta situación, el Presidente Aníbal Pinto (1876-1881) agregó una sobretasa del 10\% a los aranceles vigentes. También adoptó medidas impopulares, como el despido de empleados públicos, el varamiento en seco de buques navales y la baja de numerosas unidades del ejército y la armada. La crisis política, la más intensa desde la declaración de la independencia, dejó al descubierto una crisis social incipiente.

En 1878, el Congreso sancionó una ley que modificaba el código arancelario: a partir de ese año, se gravaron con un impuesto del 35\% los artículos suntuarios y los bienes que competían con los productos nacionales, mientras que el tributo aplicado a los bienes de capital alcanzaba apenas el $15 \%$. Otros bienes quedaron sujetos a un impuesto del 25\% o un impuesto específico basado en el valor del producto. Asimismo, se presentaron proyectos para gravar las donaciones y las herencias, así como los ingresos y las inversiones, pero finalmente se rechazaron estas medidas.

Hacia 1870, se habían hallado depósitos de nitrato de sodio en la desértica provincia peruana de Tarapacá. En las minas de plata bolivianas de Caracoles trabajaban casi exclusivamente obreros chilenos, cuya condición en territorios extranjeros, sobre todo en Bolivia, desencadenó una crisis internacional que en 1879 llevó a un enfrentamiento armado entre Chile y las fuerzas aliadas del Perú y Bolivia. La guerra del Pacífico habría de ser la experiencia más traumática vivida por Chile desde su independencia.

\footnotetext{
8 La controversia entre los "papeleros" - que apoyaban la inconvertibilidad - y los "oreros" - que propugnaban la convertibilidad en oro - se transformó en un elemento integral de la lucha política durante la mayor parte de la República Parlamentaria (18911925).
} 


\section{La guerra y la política fiscal}

Como se mencionó, desde los primeros años de independencia hasta la crisis de mediados de la década de 1870, el presupuesto nacional se sufragó, sobre todo, con los aranceles aduaneros. Sin embargo, la crisis económica redujo estos ingresos a la mitad. Por consiguiente, los principales componentes de la recaudación tributaria pasaron a ser el estanco (licencia comercial), la alcabala (impuesto a las transferencias) y el impuesto sobre la tierra (propuesto años atrás por Rengifo). No obstante, así como estos impuestos no bastaron para financiar el déficit fiscal durante la crisis económica, tampoco fueron suficientes para financiar la guerra.

Presionado por la crisis internacional, en 1879 el Congreso aprobó la mobiliaria (impuesto sobre la renta), que había sido rechazada el año anterior. El Gobierno también intentó obtener empréstitos, pero los bancos del país no pudieron prestar ayuda dada la situación precaria del sistema bancario tras la crisis de 1876. Como último recurso, las autoridades optaron por imprimir papel moneda, que el público se vio forzado a aceptar. Puesto que al imprimir dinero inevitablemente se genera inflación, fue menester adoptar alguna medida para impedir que el Gobierno recurriera en forma indefinida a esta solución.

Este problema se resolvió cuando Chile ocupó los territorios ricos en recursos controlados originalmente por el Perú y Bolivia al inicio del conflicto. En septiembre de 1879, se impuso un nuevo tributo sobre las exportaciones - equivalente a 1,60 dólares por quintal de nitrato-, gravamen que originó un flujo de ingresos fiscales suficiente para financiar el presupuesto nacional.

Si bien el Gobierno chileno tenía la opción de gravar la producción de nitrato, desde el punto de vista legal, las minas aún pertenecían al Gobierno peruano. Para salvar este escollo, las minas de nitrato se restituyeron a sus propietarios originales: sobre todo compañías británicas a las que el Gobierno del Perú anteriormente había otorgado la propiedad. Esta política permitió a empresarios privados tomar el control de la que devino la fuente primordial de recaudación tributaria durante los siguientes 50 años.

\section{La profundización de la crisis política}

La guerra no detuvo el deterioro de la situación política de Chile: por ejemplo, en 1881 un grupo de diputados intentó interrumpir el flujo de fondos destinados a las acciones bélicas con el objeto de presionar al Presidente Aníbal Pinto para que cambiara su gabinete. De hecho, esta crisis terminó gracias a los cuantiosos ingresos que comenzaron a percibirse al concluir el mandato del Presidente Pinto y que permitieron a varios municipios emprender mejoras. Mientras tanto, el propio Gobierno se embarcó en un programa de construcción de caminos y completó varias líneas ferroviarias.

El siguiente mandatario, Domingo Santa María (1881-1886) - también un liberal - debió lidiar con un Congreso que procuraba debilitar el sistema presidencial mediante la eliminación del poder de veto que el Presidente tenía sobre el gabinete y la promoción de elecciones libres de toda intervención. Como el Presidente deseaba mantener las prerrogativas de su cargo, la relación entre estos dos poderes del Estado fue bastante antagónica. El Presidente también deseaba reducir la poderosa influencia que la Iglesia católica ejercía en la sociedad chilena. Durante su mandato y en medio de una crisis desatada por el derecho de nombrar al arzobispo de Santiago, cortó las relaciones con la Santa Sede.

Tras estos acontecimientos, se sancionaron leyes sobre el matrimonio civil y el registro civil. Se crearon cementerios seculares y, a raíz de protestas del clero, se promulgó un decreto que prohibía los cementerios privados. Según Galdames (1964), la resistencia que opuso el clero fue tan fuerte que el país parecía al borde de una revolución. 
Durante esta disputa entre el Presidente y la Iglesia, los liberales (el partido del Presidente) lucharon por restringir el poder presidencial. Se llevó a cabo una reforma que amplió el sufragio a todos los hombres alfabetizados de más de 25 años (las mujeres aún no tenían derecho a voto). Esta reforma apuntaba a reducir la influencia que el Presidente podía ejercer en las elecciones, que desde la época de los regímenes conservadores había sido muy fuerte. Las elecciones legislativas de 1885 (el nuevo Congreso tenía el derecho a elegir el próximo presidente) resultaron las más violentas de la historia nacional (Collier y Sater, 2004).

Cuando José Manuel Balmaceda (miembro del Partido Liberal) asumió la presidencia el 18 de septiembre de 1886, el ambiente político estaba sumamente polarizado entre los defensores y los detractores del sistema presidencial. El Presidente Balmaceda concibió la idea de utilizar los cuantiosos ingresos provenientes de la explotación de nitrato en los nuevos territorios para financiar un ambicioso plan de obras públicas (en 1887 creó el Ministerio de Obras Públicas, que hacia 1890 consumía un tercio del presupuesto fiscal).

Podría decirse que este programa de obras públicas, sin precedentes en Chile, fue una forma de mantener el poder presidencial y menoscabar a la oposición. De hecho, dado el peligroso clima político imperante en la época, la oposición consideraba que los proyectos de obras públicas de Balmaceda representaban una forma de ampliar el clientelismo presidencial.

Esto era claro para Valentín Letelier, uno de los liberales más destacados de aquel entonces. En 1891, dictó la conferencia "La tiranía y la revolución" en la Facultad de Derecho de la Universidad de Chile, con el objetivo manifiesto de "estudiar la perniciosa influencia que la política del despotismo ha ejercido en todos los rodajes de nuestra máquina administrativa" a causa de la cual se corrompe el gobierno "hasta llegar a convertirse en la más espantosa podredumbre de que hay memoria en los fastos de la República". Y agrega que, "por otra parte, el exorbitante enriquecimiento del Fisco, mal proporcionado con el incremento de la fortuna particular, acabó de convertir al Poder Ejecutivo en el poder político más fuerte que hemos tenido desde los tiempos de O'Higgins [héroe de la independencia de Chile]. Nunca hubo antes en Chile tan gran número de empleados, de contratistas, de trabajadores, de ingenieros, de arquitectos, etc., cuya subsistencia y cuya fortuna dependieran directa y exclusivamente del Fisco. Los proveedores de madera, de cal, de ladrillo, de piedra de construcción, de hierro y de otros materiales, cuya suerte ha tenido en sus manos el Ministerio de Obras Públicas, se cuentan por centenares y centenares. Y la construcción de puentes, de caminos, de ferrocarriles, de telégrafos, de escuelas, de templos, de casas fiscales vinculó tantos intereses al Fisco que muchos de los ciudadanos más influyentes de cada departamento se consideraron obligados al Presidente de la República por obras que juzgaban deber a la munificencia y a la gracia de este magistrado" (Cavieres, 2001).

El Presidente Balmaceda también asignó una cantidad sin precedentes de recursos a la modernización del Ejército y la Armada. La justificación tradicional de esta medida se sustentó en la amenaza que presentaban para Chile los países vecinos. Sin embargo, parece más plausible que el Presidente haya tratado de ganarse la lealtad de ambos brazos de las fuerzas armadas en caso de que el conflicto político de entonces condujera a una situación de violencia. Esto parece particularmente razonable dada la mayor presencia de miembros del ejército en cargos gubernamentales de alto nivel y los incentivos otorgados al personal de la armada que apoyaran públicamente al Gobierno9 .

En noviembre de 1889, Balmaceda perdió la mayoría en ambas cámaras del Congreso y su popularidad cayó en picada. La oposición gozaba de un amplio apoyo entre los políticos, los medios y los empresarios. Además, una ola de huelgas - la primera en la historia republicana del país-

9 Dos años de salarios para las tripulaciones de los buques de guerra que renunciaran a las acciones contra el Poder Ejecutivo y un 25\% de aumento salarial para el personal de la armada que no tomó parte en la insurrección (Boletín de las leyes y decretos de la dictadura 1891). 
paralizó casi todas las ciudades y fue seguida de una dura represión jamás vista hasta entonces. Estos hechos persuadieron a una gran parte de la clase baja para coligarse con la oposición.

El Presidente Balmaceda estaba decidido a conservar sus poderes presidenciales, mientras que el Congreso y los partidos opositores, incluido el propio Partido Liberal al que pertenecía Balmaceda, estaban resueltos a que prevalecieran sus ideales parlamentarios y las libertades electorales. Cuando a fines de octubre concluyó el período de sesiones legislativas, el Congreso aún no había aprobado el presupuesto fiscal de 1891. En respuesta a ello, el Presidente Balmaceda decidió mantener las principales cuentas fiscales sancionadas para el año anterior, lo que equivalía a un acto inconstitucional. En enero de 1891, la mayoría de ambas cámaras aprobó una moción para destituir al Presidente Balmaceda y encomendó a la armada la tarea de restituir la Constitución. Debido a que casi todos los integrantes del ejército decidieron apoyar al Presidente, estalló una guerra civil, que concluyó en agosto de 1891 con la victoria de las fuerzas del Congreso.

Balmaceda se rehusó a exiliarse. En cambio, pidió asilo en la embajada argentina. Tres semanas después de su derrota, la mañana del 19 de septiembre -el día siguiente al que concluía su mandato presidencial-, se suicidó.

Como se observa en el cuadro 1, hacia fines del mandato de Balmaceda, el déficit fiscal se aproximaba al 7\% del PIB, el más alto del siglo XIX y el cuarto mayor de la historia chilena.

Cuadro 1

Chile: presupuesto fiscal durante los mandatos presidenciales, 1833-1891

(En porcentajes del producto interno bruto)

\begin{tabular}{lccccc}
\hline Presidente & Mandato & $\begin{array}{c}\text { Recaudación } \\
\text { fiscal media }\end{array}$ & Gasto fiscal medio & Saldo fiscal medio & $\begin{array}{c}\text { Déficit al final } \\
\text { del mandato }\end{array}$ \\
\hline Joaquín Prieto & $1831-1841$ & 4,0 & 4,1 & $-0,1$ & $-0,3$ \\
\hline Manuel Bulnes & $1841-1851$ & 5,4 & 5,1 & 0,3 & 0,4 \\
\hline Manuel Montt & $1851-1861$ & 5,6 & 6,0 & $-0,3$ & 0,5 \\
\hline José Joaquín Pérez & $1861-1871$ & 5,3 & 7,5 & $-2,2$ & 2,3 \\
\hline Federico Errázuriz & $1871-1876$ & 5,4 & 8,6 & $-3,1$ & 3,2 \\
\hline Aníbal Pinto & $1876-1881$ & 5,4 & 8,3 & $-2,9$ & 1,8 \\
\hline Domingo Santa María & $1881-1886$ & 7,8 & 11,3 & $-3,5$ & 5,2 \\
\hline José Manuel Balmaceda & $1886-1991$ & 9,1 & 12,7 & $-3,5$ & 6,7 \\
\hline
\end{tabular}

Fuente: G. Wagner, J. Jofré y R. Lüders, “Economía chilena 1810-1995. Cuentas fiscales”, Documento de Trabajo, N 188, Santiago, Pontificia Universidad Católica de Chile, 2000.

\section{Comentarios finales}

El período 1833-1861 se puede caracterizar por los siguientes rasgos: i) un sistema presidencial muy estable, pues solo tres mandatarios gobernaron el país y cada uno de ellos ocupó la presidencia durante diez años; ii) la supremacía de un partido - los conservadores - y la virtual inexistencia de una oposición (los liberales); iii) el progreso económico; iv) un gran respeto por la Constitución, que tenía carácter presidencialista y centralista, y v) la cohesión en torno de la figura del Presidente. Estas características indican la existencia de un ambiente de calma política. Este fue también un período de políticas fiscales sólidas.

La agitación política se desencadenó después de 1861: se desafió la hegemonía del régimen conservador, se desestabilizaron las coaliciones que apoyaban al Presidente y el Ejecutivo se vio envuelto en un conflicto permanente con el Congreso. Finalmente, la guerra civil destruyó la democracia chilena (1891). Durante este mismo período, el déficit fiscal aumentó sostenidamente. 
Los acontecimientos ocurridos entre 1861 y 1891 parecen ser evidencia de que en épocas de turbulencia política, el déficit fiscal aumenta y, por consiguiente, puede tornarse insostenible o, al menos, subóptimo. Al mismo tiempo, con estabilidad política, no hay motivos para distorsionar la política fiscal, por lo que las autoridades muy probablemente instrumentarán una política fiscal óptima.

Otra conclusión evidente que se desprende de este breve repaso de la historia chilena y que se condice con diversos modelos de los ciclos políticos presupuestarios es la actitud hacia las inversiones en obras públicas durante períodos de crisis, como en los gobiernos de Pinto, Santa María y, sobre todo, Balmaceda. En su modelo de los ciclos políticos presupuestarios, Rogoff (1990) describe la preferencia de los gobiernos por los proyectos de gran visibilidad inmediata. González (2002, pág. 220), que halló un sesgo político similar en México, plantea que las conclusiones presentadas en su trabajo tienen varias consecuencias interesantes. En primer lugar, el análisis muestra que, de hecho, el Gobierno mexicano manipuló la política fiscal con fines políticos antes de cada una de las elecciones federales y que la variable de política utilizada parece haber sido el gasto en infraestructura. Cierta evidencia sugiere que el auge de la inversión pública comienza relativamente temprano en el ciclo político (al menos, seis trimestres antes de la elección), continúa por lo menos hasta el último trimestre previo al sufragio y luego disminuye cuando se alcanza el trimestre de la votación.

\section{Bibliografía}

Bai, J. (1997), "Estimation of a change point in multiple regression models", Review of Economics and Statistics, vol. 79, № 4, Cambridge, Massachusetts, The MIT Press.

Bai, J. y P. Perron (2003), "Computation and analysis of multiple structural change models", Journal of Applied Econometrics, vol. 18, № 1, Wiley.

(1998), "Estimating and testing linear models with multiple structural changes", Econometrica, vol. 66, $N^{\circ}$ 1, Nueva York, The Econometric Society.

Cáceres, J. (2000), “Guerra y finanzas públicas en Chile y Perú: 1860-1890”, Revista de Humanidades, № 7 , Santiago, Universidad Andrés Bello.

Cashin, P., N. Haque y N. Olekalns (1999), "Spend now, pay later? Tax smoothing and fiscal sustainability in South Asia", IMF Working Paper, N WP/99/63, Washington, D.C., Fondo Monetario Internacional.

Castedo, L. (2001), Vida y muerte de la República Parlamentaria, Santiago, Editorial Sudamericana.

Cavieres, E. (2001), "Anverso y reverso del liberalismo en Chile", Historia, vol. 34, Santiago, Pontificia Universidad Católica de Chile.

Cerda, R. y R. Vergara (2008), "Government subsidies and presidential election outcomes: evidence for a development country", World Development, vol. 36, № 11, Amsterdam, Elsevier.

Collier, S. (2003), Chile: the Making of a Republic, 1830-1865, Nueva York, Cambridge University Press.

Collier, S. y W.F. Sater (2004), A History of Chile 1808-2002, Cambridge, Cambridge University Press.

Corbo, V. y L. Hernández (2005), "Ochenta años de historia del Banco Central de Chile", Economía Chilena, $N^{\circ}$ 3, Santiago, Banco Central de Chile.

Cortés, D.H., A. Butelmann y P. Videla (1981), "Proteccionismo en Chile: una visión retrospectiva”, Cuadernos de Economía, N 54-55, Santiago, Pontificia Universidad Católica de Chile.

Díaz, J. y G. Wagner (2004), "Política comercial: instrumentos y antecedentes. Chile en los siglos XIX y XX", Documento de Trabajo, № 223, Santiago, Pontificia Universidad Católica de Chile.

Díaz, J., R. Lüders y G. Wagner (2007), "Economía chilena 1810-2000. Producto total y sectorial. Una nueva mirada", Documento de Trabajo, № 315, Santiago, Pontificia Universidad Católica de Chile.

Edwards, A. (1932), El gobierno de Don Manuel Montt 1851-1861, Santiago, Editorial Nascimento.

Galdames, L. (1964), A History of Chile, Nueva York, Russell and Russel Inc.

González, M. (2002), "Do changes in democracy affect the political budget cycle? Evidence from Mexico", Review of Development Economics, vol. 6, № 2, Wiley.

Humud, C. (1969), "El sector público chileno entre 1830 y 1930", tesis, Santiago, Universidad de Chile.

Millar, R. (1994), Políticas y teorías monetarias en Chile 1810-1925, Santiago, Universidad Gabriela Mistral.

Ortega, L.M. (1897), "Change and crisis in Chile's economy and society, 1865-1879”, tesis, Universidad de Londres. 
Pastén, R. y J.P. Cover (2015), "Tax tilting and politics: some theory and evidence for Latin America”, Journal of Macroeconomics, vol. 44, Amsterdam, Elsevier.

- (2011), "Does the Chilean government smooth taxes? A tax-smoothing model with revenue collection from a natural resource", Applied Economics Letters, vol. 18, № 5, Taylor \& Francis.

- (2010), "The political economy of unsustainable fiscal deficits", Cuadernos de Economía, vol. 47, № 136, Santiago, Pontificia Universidad Católica de Chile.

Robles-Ortiz, C. (2010), "Ideología agraria y política económica en una economía exportadora: Chile 18601880", Iberoamericana, vol. 10, № 38.

Rogoff, K. (1990), "Equilibrium political budget cycles", American Economic Review, vol. 80, № 1, Nashville, Tennessee, American Economic Association.

Stuven, A. (1997), "Una aproximación a la cultura política de la elite chilena: concepto y valoración del orden social (1830-1860)", Estudios Públicos, №66, Santiago, Centro de Estudios Públicos.

Sutter, C.C. y O. Sunkel (1982), La historia económica de Chile 1830-1930: dos ensayos y una bibliografía, Madrid, Ediciones Cultura Hispánica del Instituto de Cooperación Iberoamericana.

Wagner, G., J. Jofré y R. Lüders (2000), "Economía chilena 1810-1995. Cuentas fiscales", Documento de Trabajo, № 188, Santiago, Pontificia Universidad Católica de Chile. 